\title{
Real-time terahertz imaging for art conservation science
}

\author{
K. Fukunaga \\ kaori@nict.go.jp \\ N. Sekine \\ I. Hosako \\ N. Oda \\ H. Yoneyama
}

T. Sudoh
National Institute of Information and Communications Technology, Tokyo, Japan

National Institute of Information and Communications Technology, Tokyo, Japan

National Institute of Information and Communications Technology, Tokyo, Japan

NEC Corporation, Tokyo, Japan

NEC Corporation, Tokyo, Japan

NEC Avio Infrared Technologies Co., Ltd., Tokyo, Japan

A new real-time terahertz imaging system has been developed by using a quantum cascade laser source and a microbolometer focal plane detector array. The application to non-invasive analyses of cultural heritage is demonstrated with an oil paint specimen. The experimental results suggested that the terahertz imaging system can identify materials based on a spectral database with a spatial resolution of about $300 \mu \mathrm{m}$. The transmission imaging indicated the difference between natural and artificial ultramarine pigments. Since the size of the system is similar to a common portable infrared camera, it can be used at the place where the object is located, such as museums, and can contribute to conservation activities, such as drying process monitoring. This real-time, small, non-invasive terahertz imaging system can be used in various fundamental research fields and practical industries. [DOI: 10.2971/jeos.2008.08027]

Keywords: terahertz, realtime-imaging, material analysis

\section{INTRODUCTION}

Terahertz (THz) spectroscopy and imaging is an emerging technology in the optics research field $[1,2]$. In security applications, such as hidden explosives and illegal drug detection, several systems have been used in practice, and real time imaging systems have been proposed [3]-[5]. There is an attempt to analyse fresco paintings, and the work suggests that $\mathrm{THz}$ imaging can reveal paint under the plaster [6] for some pigments. We have developed a spectral database of 200 or more art materials including mineral pigments, organic dyes, natural resins, oils, and synthetic resins to apply terahertz spectroscopy for art conservation science [7]. The specimens were selected based on the conservation activities using $X$ ray, ultraviolet, near- and mid infrared technologies and the Raman spectroscopy [8, 9]. By using tempera painting models and real medieval parchment specimens, we have demonstrated that terahertz imaging can indicate a difference beween materials that have the same colour to the naked eye, either in transmission [10] or in reflection [11]. These results prove that $\mathrm{THz}$ techniques can be used not only to find "something different" among the materials used, but also to identify the materials based on the database. The previous systems, however, are large and cannot be moved to museums or in front of mural paintings. We have developed a small terahertz imaging system by using a quantum cascade laser (QCL) [12] and a $320 \times 240$ microbolometer focal plane array (FPA) [13] and examined the possibility of applying it to art material analyses.

\section{EXPERIMENTAL}

Figure 1 shows the schematic diagram of the $\mathrm{THz}$ imaging system and a photograph of the measurement setup used in this work. The distances between components was determined to image around $5 \mathrm{~mm}$ square of the specimen. The

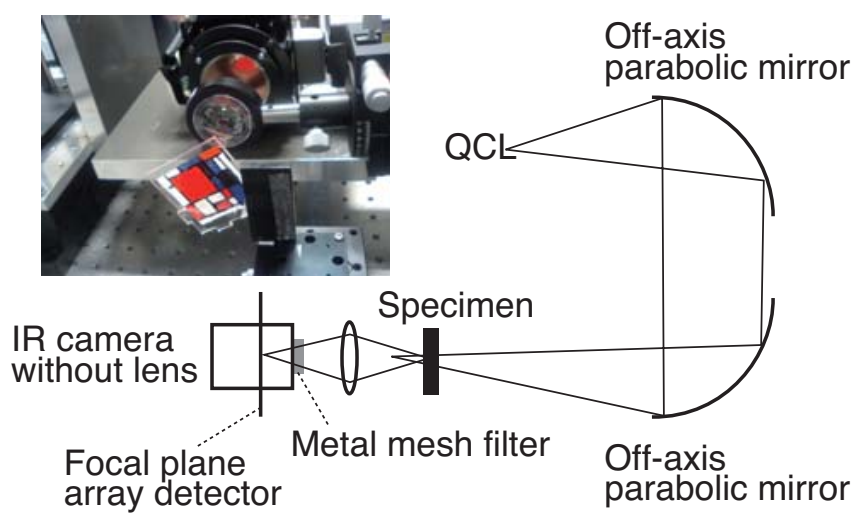

FIC. 1 Schematic diagram and photograph of small terahertz imaging system. 
(b)

(a)

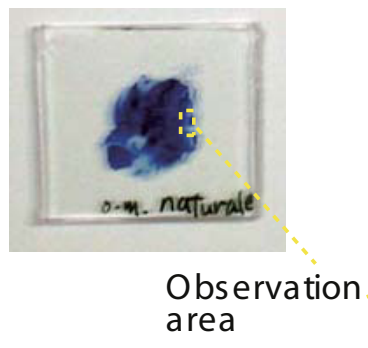

FIG. 2 Specimens (a) Natural Ultramarine (Lapis), (b) Four colour composition.

QCL source provides radiation of $3.1 \mathrm{THz}$ and time averaged power of around $10 \mu \mathrm{W}$. It was collimated by an off-axis parabolic (OAP) mirror and was led to irradiate a specimen by another OAP. The transmitted $\mathrm{THz}$ radiation through the specimen was detected by the FPA detector via a lens with $25 \mathrm{~mm}$ in diameter. The FPA has a pixel pitch of $23.5 \mu \mathrm{m}$ and its frame rate is $60 \mathrm{~Hz}$. During imaging experiments, pixel integration and frame integration were carried out. Signals from pixels of $3 \times 3$ were integrated and 64 frames were integrated to improve signal-to-noise ratios. A noise equivalent power value of $1 \mathrm{pW}$ was achievable. The spatial resolution is not defined by the integrated pixel size, but is defined by the Fraunhofer diffraction limit of the lens which is estimated to be $256 \mu \mathrm{m}$. Details of the FPA are described in [13].

Figure 2 shows specimens which were painted by using pigments of which $\mathrm{THz}$ spectra were in the data base, with a mixture binder of linseed oil and petrol on a cycro-olefin plate of $2 \mathrm{~mm}$ thick. The mixture binder and the plate have no specific absorption in the frequency range of the measurement. Figure 2(a) was painted by natural ultramarine which absorbs strongly in the $\mathrm{THz}$ region, and the data were used to examine the spatial resolution in practice. Figure 2(b) was painted by several pigments with the mixture of linseed oil and petrol, including cadmium red $(\mathrm{Cd})$, lead white $(\mathrm{Pb})$, cinnabar (HgS), natural ultramarine (Lapis), artificial ultramarine (UM), and lamp black which was painted with a synthetic resin PVA or linseed oil. Spectra of these materials registered in the database [7] are shown in Figure 3. These were obtained by a Fourier transform spectrometer (JASCO FARIS1) with a frequency range from 0.5 to $15 \mathrm{THz}$. We also observed the transmission characteristics of actual painted materials in this work by a time domain spectroscopy (TDS) system (Tochigi Nikon) as shown in Figure 4(a). Although the frequency range of THz-TDS is limited up to around $4 \mathrm{THz}$, there is a possible application of three dimensional observation. As some of the spectra show in Figure 3, transmission of $\mathrm{Cd}, \mathrm{Zn}, \mathrm{UM}$ was high at the measurement frequency $3.1 \mathrm{THz}$, and others were not. The lower transmission means that the pigments absorb or reflect the electromagnetic waves in the $\mathrm{THz}$ region. The complex refractive index can be directly calculated based on the time domain spectra which include intensity and phase information, when a specimen is perfectly homogeneous with no influence of scattering at the surface and inside the material. Since the paint is a mixture of pigments and binders, the calculated refractive index results in

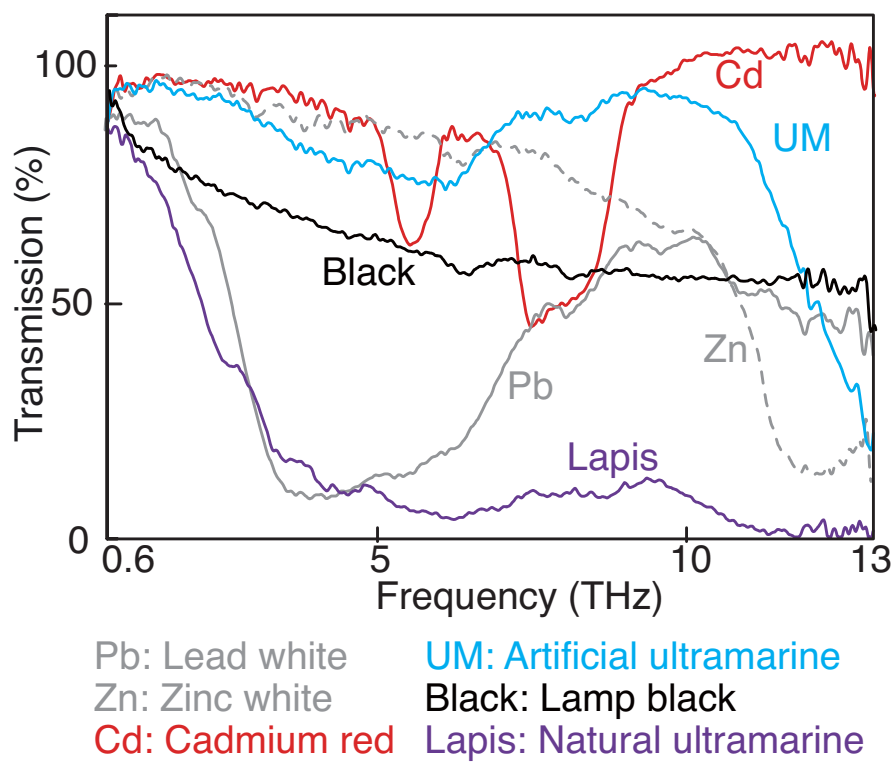

FIG. 3 Spectra of pigments used in specimens. (a)

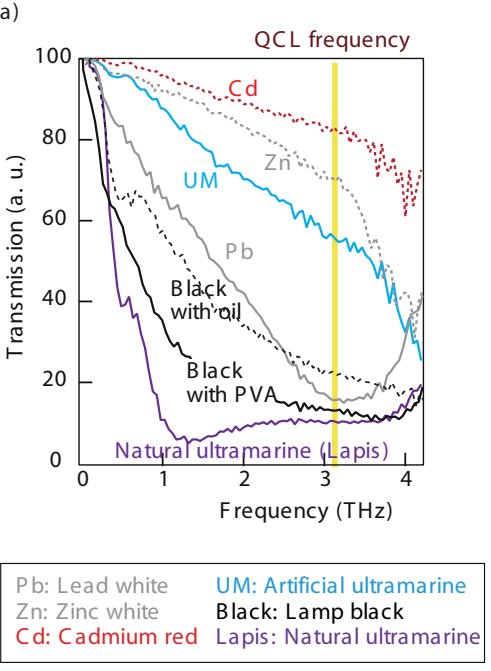

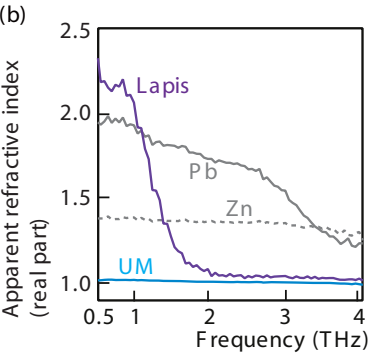

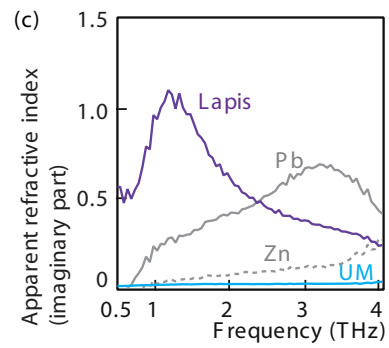

FIG. 4 Spectra and apparent refractive index of actual painted materials (mixture of pigments and binders), (a) spectra, (b) real part fo refractive index, (c) imaginary part of refractive index.

an "apparent" value. In this work, specimens were prepared to show colours as model paintings, and the physical properties were not strictly controlled. For example, size and shape of pigments vary, and the pigment/binder ratio was not specified. Figure 4(b) and 4(c) show examples of the refractive index of lead white, zinc white, natural and artificial ultramarine pigments painted with linseed oil. According to paint manufacturers' general information, the real part of the refractive index of a bulk of lead white and zinc white in the visible region is around 2.0, that of ultramarine is around 1.5, and that of oil is around 1.5. The frequency response of the apparent refractive index and the difference between the measured values and those supplied from manufacturers are considered to be due to the size and shape of pigments as well as surface conditions of painted area. Although further investigation is required to clarify the physics of the complex refractive index of paints, the difference can be used to distinguish between two sets of white and blue pigments in practise. 


\section{RESULTS}

Figure 5 shows visible and $\mathrm{THz}$ transmission images of a specimen with natural ultramarine. The yellow broken line indicates the observation area by the $\mathrm{THz}$ imaging system. The $\mathrm{THz}$ false colour images represent the transmission level from blue to red as in the colour-bar in the figure. As shown in the super-imposed figure on the right hand side, the painted area has low transmission (blue-green) and the area without pigments shows yellow-red. Judging from the obtained image, the resolution is around $300 \mu \mathrm{m}$ which is in good agreement with the calculated values. Here, the noise line was due to fixed pattern noise, and will be eliminated by a lock-inthermography technique in the near future.

Figure 6 shows an examle of $\mathrm{THz}$ transmission images of the four colour specimen. The PVA based black frame has low transmission, resulting in a blue colour. The oil based black area containing the same black pigment has a slightly higher transmission than the area with PVA. The cadmium red area has a high transmission appearing as a red-yellow-green colour. The difference between natural ultramarine (lapis) and artificial ultramarine is clearly observed by $\mathrm{THz}$ imaging. The low transmission of natural ultramarine might be due to strong absorption by internal crystalline water although precise investigation is required to clarify the reason.

These experimental results prove that $\mathrm{THz}$ imaging using a simple setup of a QCL and microbolometer FPA detector can distinguish white pigments in real time, with a resolution of

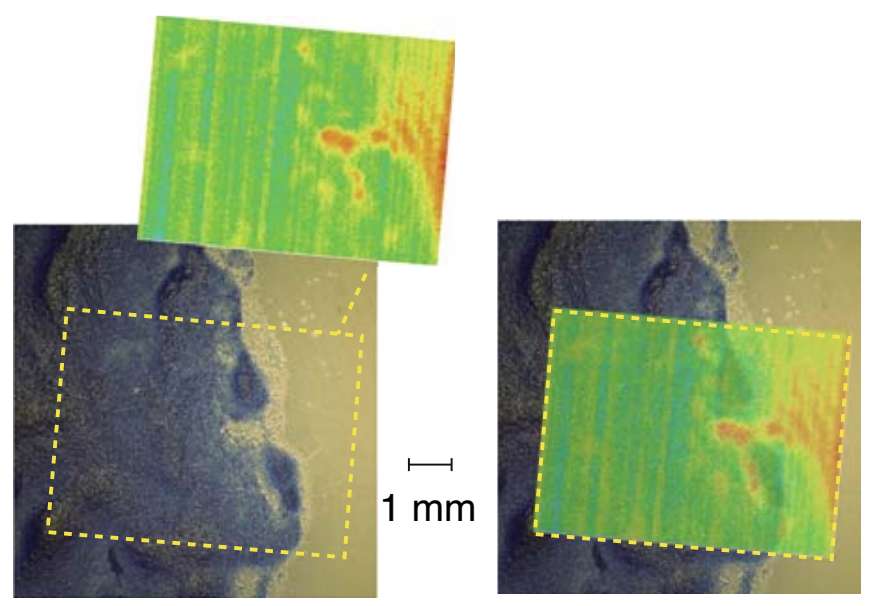

FIG. 5 Terahertz imaging of ultramarine specimen. (a) Visible image

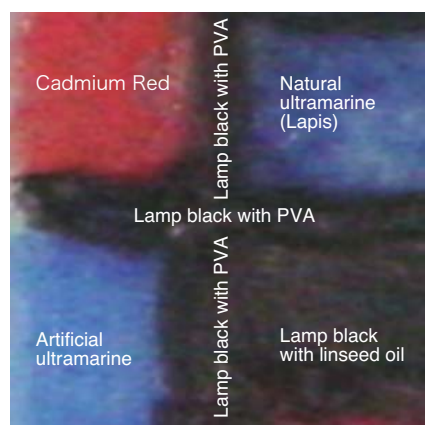

(b) THz image

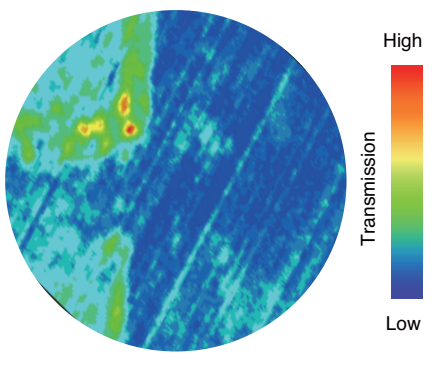

FIG. 6 Terahertz imaging of four colour specimen. about $300 \mu \mathrm{m}$. The configuration of the parts can be optimised depending on the observation targets. It is expected that spectroscopic imaging by using QCLs with different frequencies is possible in real-time with a small portable system based on the setup used in this work.

\section{CONCLUSIONS}

We have developed a real-time small $\mathrm{THz}$ imaging system and applied it to art material analyses. Although further investigation is required to establish appropriate measurement and interpretation methods of the artistic objects by using $\mathrm{THz}$ spectroscopy, the experimental results with the THz imaging system show the high prospects of developing a real-time, high resolution, portable $\mathrm{THz}$ imaging system. The system should contribute to conservation science, including drying process monitoring, non-invasive pigment and binder analysis, and we believe that the application of real-time portable imaging system will be enlarged to various industries as a new noninvasive monitoring technique.

\section{References}

[1] B. B. Hu, and M. C. Nuss, "Imaging with terahertz waves" Opt. Lett. 20, 1716 (1995).

[2] D. Mitteleman, R. H. Jacobsen, and M. C. Nuss, "T-ray imaging" IEEE J. Quantum Elect. 2, 679-692 (1996).

[3] A. W. M. Lee, B. S. Williams, S. Kumar, Q. Hu, and J. L. Reno, "Real-time imaging using a $4.3 \mathrm{THz}$ quantum cascade laser and a $320 \times 240$ microbolometer focal-plane array" IEEE Photonic Tech. L. $18,1415-1417$ (2008).

[4] T. Yasui, K. Sawanaka, A. Ihara, E. Abraham, M. Hashimoto, and T. Araki, "Absorption-sensitive diffuse reflection imaging of concealed powders using a terahertz quantum cascade laser" 0 pt. Express 16, 1208-1221 (2008).

[5] P. Dean, M. U. Shaukat, S. P. Khanna, S. Chakraborty, M. Lachab, A. Burnett, G. Davies, and E. H. Linfield, “Absorption-sensitive diffuse reflection imaging of concealed powders using a terahertz quantum cascade laser" Opt. Express 16, 5997-6007 (2008).

[6] J. B. Jackson, M. Mourou, J. F. Whitaker, I. N. Duling III, S. L. Williamson, M. Menu, and G.A. Mourou, "Terahertz imaging for non-destructive evaluation of mural paintings" Opt. Commun. 281, 527-532 (2008).

[7] http://www.thz-spectra.com/

[8] M. R. Derrick, D. Stulik, and J. M. Lanfry, Infrared Spectroscopy in Conservation Science (The Getty Conservation Institute, Los Angeles, 1999).

[9] A. Aldrovandi, M. L. Altamura, M. T. Cianfanelli, and P. Riitano, "Pictorial materials: the creation of a sample charge for the characterization of materials by means of multispectral analysis" OPD Restauro 8, 191-210 (1996).

[10] K. Fukunaga, Y. Ogawa, S. Hayashi, and I. Hosako, “Terahertz spectroscopy for art conservation" IEICE Electron. Express 4, 258-263 (2007).

[11] A. Doria, E. Giovenale, G. P. Gallerano, G. Messina, A. Petralia, I. Spassovsky, K. Fukunaga, and I. Hosako, "THz-ARTE: non-invasive terahertz diagnostics for art conservation" Proc. IRMMW-THz 2008, in preparation (2008). 
[12] I. Hosako, N. Sekine, M. Patrashin, and H. Yasuda, "Development of components for cost effective terahertz measurement system: terahertz quantum cascade laser and terahertz quantum well infrared photo-detector" Proc. SPIE 6772, 67720R-67720R9 (2007).
[13] N. Oda, H. Yoneyama, T. Sasaki, M. Sano, S. Kurashina, I. Hosako, N. Sekine, T. Sudoh, and T. Irie, "Detection of terahertz radiation from quantum cascade laser using vanadium oxide microbolometer focal plane arrays" Proc. SPIE 6940, 69402Y-69402Y12 (2008). 